\title{
How to Effectively and Efficiently Communicate Research Results? Experimental Study on the Influence of Interactivity and Presentation form on Knowledge Transfer and Cognitive Activity
}

\author{
Andreas Krämer ${ }^{1,2}$, Sandra Böhrs ${ }^{3}$ \& Susanne Ilemann ${ }^{3}$ \\ ${ }^{1}$ exeo Strategic Consulting AG, Bonn, Germany \\ ${ }^{2}$ Value Research Institute, Iserlohn, Germany \\ ${ }^{3}$ Simpleshow S.A., Luxembourg \\ Correspondence: Prof. Dr. Andreas Krämer, exeo Strategic Consulting AG, Wittelsbacherring 24, 53115 Bonn, \\ Germany. E-mail: andreas.kraemer@exeo-consulting.com
}

Received: May 10, 2021 Accepted: June 17, 2021 Online Published: June 24, 2021

doi:10.5539/jel.v10n4p87 URL: https://doi.org/10.5539/jel.v10n4p87

\begin{abstract}
When it comes to presenting research results, the usual approach is to use PowerPoint or similar slide applications, or to opt for alternative presentation tools. A central question is how well the knowledge is transferred and to what extent the target audience is addressed emotionally. Based on a $2 * 2$ factorial design, the effects of presentation form (PowerPoint slide presentation vs. explainer video) and interaction (no interaction vs interaction by means of additional questions on the topic) were investigated. Overall, the presentation factor is more important for learning success than the interaction factor and explainer videos perform significantly better than the PowerPoint presentation. This applies to the objective and subjective learning success, but also to the emotional appeal and the increase in engagement, interest and other cognitive activities. The effects of the interaction factor are relatively low, achieving minor improvements in combination with the PowerPoint presentation, while no statistically significant and relevant effects were found in combination with the explainer video.
\end{abstract}

Keywords: slide presentation, interactivity, explainer video, experimental online survey, learning effects

\section{Introduction}

In a world with an overabundance of information sources, contradictory statements and increasing complexity, the efficiency of knowledge transfer is a key challenge. In order to improve the learning process four main elements are emphasized: learning result (knowledge achievement), content type, learning method and delivery media (Clark, 2008; Rusli et al., 2014). When it comes to delivery media there are considerable controversies regarding advantages and disadvantages of different multimedia. Here, the level of interactivity and the type of visualization are two prominent facettes (Koć-Januchta et al., 2020).

The question of how to communicate research results effectively and efficiently is not only important for the school or university sector, but also for companies. In this context, two developments concerning the factor delivery media should be considered. First, traditional forms of knowledge transfer, such as the use of slide presentations, represent the standard, despite various criticisms, both in the field of education and business. Second, consumer preferences are changing at a rapid pace in favor of videos (Krämer \& Böhrs, 2020) while at the same time the trend of MOOCs (Massive Open Online Courses) leads to the usage of videos for teaching (Khalil \& Ebner, 2013; Krämer \& Böhrs, 2015). Although there are examples of companies abandoning the use of PowerPoint or similar slide programs altogether - the case of Amazon, where Jeff Bezos banned his employees from using PowerPoint presentations, is one of the most prominent (Ciriello et al., 2015) - these are rather isolated cases. For most companies, it is more likely that PowerPoint is judged to be virtually indispensable in everyday work. In this context, Gabrielle (2010) highlights, "PowerPoint is more than a visual aid for presenters, it has become one of the business leaders most important tools for winning in the idea market place (competition for attention, budget and headcount by selling ideas). In this logic, therefore, it is not only a matter of transmitting information, but also the aspect of persuasion and decision support. Here, a core challenge is how well the central messages reach the target persons and remain present in their minds." 
In recent years the use of videos as a learning tool has been growing steadily, driven by an increasing relevance of eLearning (Zhang \& Nunamaker, 2003) in general and ODL (Open and Distance Learning) in particular (Fozdar, 2015). Videos play a crucial role since video is by far one of the most powerful and expressive non-textual media that captures and conveys information in education (Hampapur \& Jain, 1998) and enhances creative problem-solving skills (Mayer, 1997). At the same time, companies use eLearning programs (including videos as a main element) to take advantage of the possibilities of digitization to achieve economies of scale in the transfer of knowledge among employees (Derouin, Fritzsche, \& Salas, 2005).

\section{Focus on Improvements in the Learning Process}

\subsection{Explainer Videos as a Learning Tool}

Explainer videos effectively convey complex facts to a target group within a very short time (Tu, 2015; Sedej, 2019). Characterizing features are storytelling and multisensory elements (Schmelzle, 2014; Wright, 2004). Explainer videos are usually one to three minutes long. Rather than going into detail, they focus on the most relevant facts. The visualization includes animated illustrations, graphics, or photos. There are different types of explainer videos, such as paper cut-out or so-called papermation videos, live scribble, whiteboard animation, or fully animated explainer videos (Kulgemeyer, 2018). In recent years, a larger number of providers have established themselves that enable the independent online creation of videos, with explainer videos representing only one aspect. One particularly prominent example is the DIY platform Powtoon (Graham, 2015). While there are a range of other DIY animated video creator tools on the market such as Vyond or simpleshow video maker, the corporate market is still largely serviced by full-service providers, a few of the better known being Switch Video, Firestarter, epipheo, You-know, explainity and again simpleshow. The simpleshow video maker tool has a distinct approach: Here, the creation process of a video is text-based, analogous to the first step in a full-service project approach. Thereafter, the visualization is generated in the tool by artificial intelligence (AI). In an automated process (image composition, animation and sound), the customer receives an individual video based on the provided storyline (Krämer \& Böhrs, 2015).

Online video has quickly emerged as the preferred content medium for business-to-business (B2B) marketers around the world (Krämer \& Böhrs, 2016; Krämer \& Böhrs, 2017a). The scope of application (compliance, strategic topics, processes in sales and production, IT, new programs, etc.) is extremely broad (Krämer \& Böhrs, 2018; Sedej, 2019). Today, explainer videos are used at all stages of the sales cycle to educate, entertain, inspire, and engage potential customers (Litt, 2014), both in the B2B and B2C market. Another area of application is education (Laaser \& Toloza, 2017; Krämer \& Böhrs, 2015). There are different assessments regarding the performance of explainer videos as a learning tool. While some authors emphasize the innovative character, other researchers express doubts about the efficient use of such tools. Thus, Laaser and Toloza (2017) point out that "the fun effect of the animation techniques can also provoke the illusion that learning is extremely easy and that the content presented is a fast-track to acquiring knowledge". Gamble (2016) briefly and succinctly describes: "Animated explainer video shops have been growing like weeds... Here, our concern is quality...." However, there are also studies that empirically examine the learning effect of different types of explainer videos and confirm generally positive effects in knowledge transfer, but also considerable differences in the effect depending on the design (Krämer \& Böhrs, 2017b; Kulgemeyer, 2018).

\subsection{Slide Presentations as a Learning Tool}

PowerPoint, the world-leading presentation software developed by Microsoft, is used for displaying specific digital content to target audiences. The application establishes an organizational structure in slides, in which a bulleted presentation of instructional material summarizes the main ideas of instructors in a well-ordered manner (Susskind, 2008). Slide presentations have become popular because of the option to reduce complex issue to some basic aspects. As Gabriel (2008) describes: "Instead of having to plough through lengthy reports, busy business people could quickly skim through a few transparencies and absorb the essential features of a case or an argument", indicating that slide presentations are perceived as easier to comprehend compared to information provided in mere text form.

Although the program enjoys a high level of popularity, its use in education, among other areas, has been criticized. Basically, it is doubted that the tool is suitable as a learning tool (Lane, 2008). Yet, research on the effectiveness of PowerPoint as a learning tool is limited (Penciner, 2013). When comparing PowerPoint and Prezi in a classroom Chou et al. (2015) describe PowerPoint to be a cost-effective approach to delivering instructional content. In order to improve PowerPoint's effectiveness in learning success researchers and academics recommend "employing more relevant images with narration and less text" (Penciner, 2013), embedding video, audio, and hyperlink documents (Clark, 2008) or using the application as an interactive 
element of presentations (Jordan \& Papp, 2014). Despite these possibilities, the practical use is often not very innovative, PowerPoint is used by lecturers more text-based and less interactive (Pamadhi \& Zulfiati, 2019). The same applies to the business environment. Hertz, van Woerkum and Kerkhof (2013) confirm that even after more than one decade of discussion about the deficits of PowerPoint presentations, typical criticisms such as an overabundance of text or an overly monotonous presentation of results still are valid. Slide presentations can be used to give a presentation in person, but also to document results or structures. When presenting study results from market research typically a chart presentation is provided for documenting the findings (Sarstedt \& Mooi, 2014). Although the results can be communicated much better in this way than in the context of tabular reports, enthusiasm is also limited among market researchers and their clients with regard to the usual presentation of results. For this reason, alternatives have been discussed for quite some time, namely the change from PowerPoint presentation to the integration of dashboards for result summarization (Zhang et al., 2020) and substitution by new media (Brewster, 2011).

\subsection{Interaction as a Determinant for Learning Success}

Interaction is considered to be an important element to increase learning success (Geri, 2017; Koć-Januchta et al., 2020). Conversely, the absence of interactivity can be a barrier to knowledge transfer. Criticism of the use of slide presentations, for example, mainly concerns the lack of interaction (Penciner, 2013; Brewster, 2011).

There are different aspects to be considered in the interaction, among others the direction of the interaction and the form of the interaction. Garrison and Shale (1990) defined various styles of education covering content, students and teachers. In a digital multimedia environment "student-content interaction" initiated by the computer system has a particularly high relevance (Schär \& Krueger, 2000; Nandi et al., 2015).

A target audience's interaction may include reading informational texts, using study guides, watching videos, interacting with computer-based multimedia, and completing assignments and projects. But there are also risks. For example, animations may disadvantageously increase the cognitive load. The cognitive load theory (van Merriënboer \& Sweller, 2005) is linking cognitive effort to the learning process (Paas et al., 2004). In addition to images and animations, researchers have also examined the strategies of embedding questions or providing students with notes/handouts that align with the PowerPoint (Valdez, 2013). One way to reduce mental effort is to provide learners with a possibility to control the pace and sequence of processing the information (Tabbers \& de Koeijer, 2010). That way, learners have the opportunity to adjust the presentation speed to their needs i.e., subjects make use of the possibility to select relevant information and to organize and integrate it into a mental model (Mayer \& Chandler, 2001).

\subsection{Background of Study and Objectives}

Simpleshow is a media company (founded in 2008) specializing in the provision of tools and services for the creation of explainer videos, mainly in the business sector. While an accumulated full-service production volume of approximately 25,000 videos has gained simpleshow the leading position in this worldwide market, the online DIY tool simpleshow video maker has outgrown the service offering of the company in the past years. Since its launch in April 2016, a seven-digit number of online videos has been created on the digital platform by its hundreds of thousands of users. The format approach of simpleshow explainer videos is to summarize information and improve the learning outcome using empathetic storytelling and a finely tuned interplay of sound and image. This makes this charming and engaging format a perfect key element for an online course.

The general objective of the study is to explore the future prospects of explainer videos and the learning effects compared with a traditional slide presentation using a quantitative approach and taking into account different user segments and variations in video affinity. The goal is also to analyze the effectiveness (learning effect) and efficiency (ratio learning effect per time of consumed video) of the explainer video as a format to improve the knowledge base of the user in comparison with a PowerPoint presentation and to investigate moderating effects of interactive elements while presenting study results.

The basic population for the study comprises customers who have created explainer videos themselves using the DIY tool on the simpleshow video maker platform or who have commissioned the creation of explainer videos as corporate customers. Therefore, the sample is not aiming to meet population-representative structures, but to represent the customer structure of the company simpleshow well. Since Germany is a major market for simpleshow, the study was conducted in German-speaking countries.

\subsection{Research Questions}

The study aims to provide answers to the following questions:

- How strong are respondents' preferences for consuming videos on the one hand and texts on the other? 
How do the structures of the sample match the results of representative studies? Can clusters with homogeneous media preferences be identified?

- How do respondents use explainer videos and slide presentations in their private and professional lives in general, and specifically what potential exists for either replacing or expanding slide presentations with explainer videos?

- How do different presentation styles such as slide presentations and explainer videos (EV) perform in terms of knowledge effect (case study: results on the relevance of remote work during the COVID-19 crisis)? Is the integration of interactive elements (e.g., additional questions about the content shown) a key to increase knowledge transfer?

- How can the empirical results be classified in the current state of research on the learning effect of explainer videos and what recommendations can be made for the practical use of explainer videos as a substitute or supplement to a slide presentation?

\section{Method}

\subsection{Procedures and Methodology}

In order to answer the research questions, an empirical study was carried out. It provided insights into different customer segments of simpleshow. In addition to the economic benefits of an online research study, this survey type also has further substantive advantages for an experimental testing. This is particularly true when different types of information such as videos and graphics will be presented during the interview (Krämer, 2016).

The online survey - representing two different sample groups-was conducted in March 2021 and was focused on B2C (Education) and B2B (Corporate) segments (see Table 1). In total 472 interviews could be used for the analysis. The average time to complete the interview was almost 14 minutes.

Table 1. Sample groups and characteristics

\begin{tabular}{lclll}
\hline Sample group* & Interviews (field, 2021) & Respondents & Interview time & Age (years) \\
\hline \# 1 Education & March $15^{\text {th }}-24^{\text {th }}$ & $\mathrm{N}=220(47 \%)$ & $\varnothing 12.6 \mathrm{~min}$ & $\varnothing 45.5 \mathrm{y}$. \\
\# 2 Corporations & March $15^{\text {th }}-28^{\text {th }}$ & $\mathrm{N}=252(53 \%)$ & $\varnothing 14.6 \mathrm{~min}$ & $\varnothing 44.5 \mathrm{y}$. \\
Total & March $15^{\text {th }}-28^{\text {th }}$ & $\mathrm{N}=472(100 \%)$ & $\varnothing 13.7 \mathrm{~min}$ & $\varnothing 45.0 \mathrm{y}$. \\
\hline Total contacts: 29,190, net response rate $=1.6 \%$. Respondents with an unrealistic short interview time were eliminated (Note 1).
\end{tabular}

Segments differ significantly in terms of age groups, creation or commissioning of explainer videos, and simpleshow video maker (SVM) use (see Appendix A).

\subsection{Structure of the Study and the Experiment}

The survey consists of a general part in which respondents provide information about how often they use explainer videos and what their media preferences are (in particular, affinity for consuming texts vs. videos) in order to be able to cluster interviewees according to their preferences (Riding \& Douglas, 1993).

In a special part, an experiment is conducted. The framework conditions for the test groups had been identical. For the experiment, a popular topic was selected, for which actual market research data were available (Krämer $\&$ Hercher, 2021, published in Feb. 2021). The purpose of the experimental design is to test the effect of the independent and dependent variables. The independent variable is the type of presentation of actual research results concerning the relevance of remote work during the COVID-19 pandemic with two kinds of treatment: presentation (PowerPoint PPTX slides vs. explainer video, EV) and the interaction (yes = additional questions while presenting the results vs. no $=$ no additional questions while presenting the results) as the moderator variable. The type of interaction can be described by a "student-content interaction" initiated by the computer system (Schär \& Krueger, 2000, see Note 2). The dependent variable is the result of a knowledge test as well as the perceived quality of the presentation. The experimental design is ANOVA $2 \times 2$ univariat factorial experiment. Within the online survey, respondents are randomly assigned to test groups. In the final data set, the structural equality of the test groups was examined and confirmed. Before the experiment started, test subjects were asked about current employment. On the one hand, this was intended to ensure conditioning for the topic of the presentation; on the other hand, it was possible to check that, for example, the proportion of subjects with home office work was equally distributed across the test groups (Figure 1). 


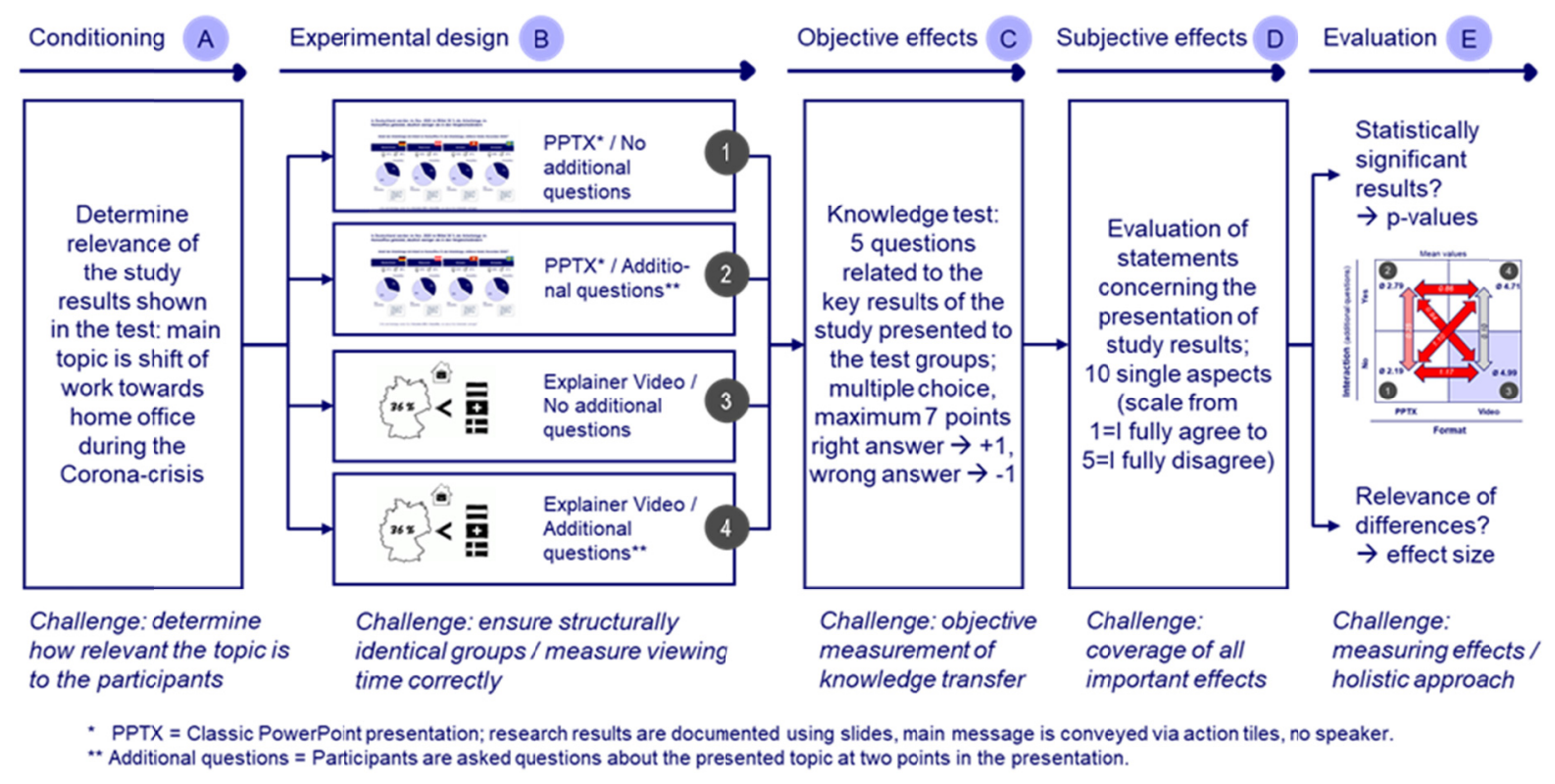

Figure 1. Different steps to conduct the experiment and specific challenges

In addition to the core areas of the study, there is a screening part at the beginning of the online interview. At the end of the interview, demographic characteristics were recorded, which later served as descriptive variables.

\subsection{Measurement of the Learning Effect (Knowledge Test)}

Having worked through the computer-presented material, participants were given a post-test for overall learning performance. Questions were related to the core findings presented to the audience. Immediately following this, participants were asked to evaluate statements measuring the individual perception of the style of presentation.

Questions to quantify learning success were derived from the reference presentation (PPTX, results from the study OpinionTRAIN 2020). At the end of the interview, participants from all test groups were given the same questions, consisting of objective questions (with standard answers). Key elements of the knowledge tests were:

- In total, 5 questions were asked after presenting the results from the market research (multiple choice). These questions covered main topics of the presentation/explainer video.

- Correct answers were rated as plus points, wrong answers were rated as minus points.

- 15 optional answers were offered: 7 correct answers (maximum result: 7 points) and 8 wrong answers (minimum result: -8 points).

\subsection{Data Analysis}

To examine the significance within the two sample groups (as well as other splits according to age group or test group) and to statistically evaluate background characteristics, the repeated measures ANOVA, given its ability to perform overall comparisons, Chi-Square tests and T-test were used. In addition to the parameters for statistical significance, the effect size is controlled in order to examine the relevance of measured differences in knowledge or perceptions (Sullivan \& Feinn, 2012). K-Means-Clustering was used for segmentation. All statistical analyses of the data are based on SPSS version 22.

\section{Results}

\subsection{Experiences with the Creation of Explainer Videos}

In the first part of the survey, study participants reported on how they use explainer videos and how often they create them themselves. More than a quarter of the respondents stated that they had not yet created any explainer videos themselves, and another quarter of the respondents stated that they had created 6 or more explainer videos themselves. As Table 2 shows, there are dependencies between the number of explainer videos produced and the customer segment. Respondents from the corporation segment indicate a lower number of created videos than respondents from the education segment (Chi-square test; $\mathrm{p}<0.001$, Cramér's V of 0.32 indicates a medium effect size). 
Table 2. Experiences with the creation of explainer videos

\begin{tabular}{llll}
\hline \# Explainer videos created* & Segment Education & Segment Corporations & Total** \\
\hline None & $12 \%$ & $41 \%$ & $27 \%$ \\
$1-5$ & $60 \%$ & $39 \%$ & $49 \%$ \\
$6+$ & $28 \%$ & $21 \%$ & $24 \%$ \\
\hline
\end{tabular}

Note. * Question: Have you already created an explainer video yourself? ** Chi-square-test: $\chi^{2}(2)=49.2, \mathrm{p}<0.001, \mathrm{~V}=0.32$ (medium effect size).

\subsection{Statements Concerning the Consumption of Videos}

In order to check the basic affinity of the study participants for videos, an evaluation of different statements on the preference and use of videos was carried out. Partially, these statements were already used in an earlier study from 2016 (population-representative study for Germany, online, $n=1,000$ ). This allows comparisons between the current study (not population-representative, only customers of the company simpleshow) and available secondary data. In addition, two statements on the experience and assessment of slide presentations were evaluated (Table 3). Around $90 \%$ of respondents agreed with the statement "For presentations or lectures I mostly use PowerPoint or other slide presentation programs". This underlines the strong use of slide presentations both, in the education as well as the business segment (Zhang et al., 2020). However, 73\% of respondents consider slide presentations to be monotonous. Employees in larger companies ( $>2,000$ employees) were particularly critical. This reflects a certain dissatisfaction with the tool as a whole or the lack of interaction (Penciner, 2013; Brewster, 2011).

Although there is a period of about 5 years between the studies, similar results emerge regarding the preference for consuming videos or texts. In the current study, the statement "I prefer watching videos to reading texts" receives a mean agreement of 2.6 , while this was 2.7 in the reference study $(1=\mathrm{I}$ fully agree to $5=\mathrm{I}$ fully disagree). A presumed bias in media preference in favor of video (determined by experience with explainer videos) cannot be confirmed. Mean values in both samples are similar (effect size below the threshold of $5 \%$ deviation). A strong age dependence in video preference is also present in both studies (see Appendix B).

When comparing the effect sizes (Cohens' d), in most cases values are below the threshold of 0.2. It can therefore be assumed that there are no relevant differences. Only in the case of the statement "I prefer reading texts to watching a video", differences between the studies have a low relevance $(\mathrm{d}=0.37)$.

Table 3. Statements concerning the consumption of videos (mean values, $\%$ top- 2 agreement in brackets)

\begin{tabular}{|c|c|c|}
\hline Evaluation of statements (rating scale)* & $\begin{array}{l}\text { Current study: } \\
\text { German-speaking customers (2021) }\end{array}$ & $\begin{array}{l}\text { Reference study } \\
\text { Germany }(2016)^{* *}\end{array}$ \\
\hline $\begin{array}{l}\text { For presentations or lectures I mostly use PowerPoint } \\
\text { or other slide presentation programs. }\end{array}$ & $1.67(90 \%)$ & Not asked \\
\hline Videos that explain something must be short. & $1.82(84 \%)$ & Not asked \\
\hline Many presentations or result reports in slide form are too monotonous for me. & $2.08(73 \%)$ & Not asked \\
\hline I can remember videos better than text content. & $2.29^{0.22}(62 \%)$ & $2.5(52 \%)$ \\
\hline I prefer watching videos to reading texts. & $2.61^{0.07}(49 \%)$ & $2.74(43 \%)$ \\
\hline I often watch videos on my smartphone, because I can't read texts as well on it. & $2.83^{0.11}(43 \%)$ & $3.58(23 \%)$ \\
\hline If I'm searching for information, I often watch a video. & $2.85^{0.11}(43 \%)$ & $2.99(39 \%)$ \\
\hline I prefer reading texts to watching a video. & $3.44^{0.37}(16 \%)$ & $2.99(29 \%)$ \\
\hline
\end{tabular}

\subsection{Customer Segments Concerning Text-Video-Orientation}

Based on the statements presented on media orientation, a cluster analysis was carried out in which three different groups could be identified. The group of text-oriented people $(22 \%)$ gives priority to texts over videos when searching for and absorbing information (Table 4). Here, the level of agreement with the statement "If I'm searching for information, I often watch a video" is low (69\% disagreement), while agreement with the statement "I prefer to read texts to watching a video" is high (67\% agreement). The group of video-oriented subjects (39\%) shows a high affinity for using videos at the expense of texts. There is no pronounced affinity for video or text 
among the third group of individuals (39\%, segment "indifferent").

Table 4. Customer segments according to statement evaluation (media orientation)

\begin{tabular}{llll}
\hline Media-orientation* & Segment Education & Segment Corporations & Total sample** \\
\hline Text-oriented & $28 \%$ & $17 \%$ & $22 \%$ \\
Text-video indifferent & $39 \%$ & $39 \%$ & $39 \%$ \\
Video-oriented & $34 \%$ & $44 \%$ & $39 \%$ \\
\hline
\end{tabular}

Note. * Question: To what degree do you agree with the following statements? (Scale from $1=$ I fully agree to $5=\mathrm{I}$ fully disagree). Cluster analysis by K-means algorithm.

** Chi-square-test: $\chi^{2}(2)=9.8, \mathrm{p}=0.007, \mathrm{~V}=0.14$ (small effect).

The orientation in favor of video and at the expense of text information is comparatively more pronounced in the corporate segment (statistically significant, small effect size).

Regardless of a stronger affinity to texts or to videos, the statements on the use of slide presentations do not strongly differ. For example, more than $96 \%$ of respondents assigned to the text-oriented group stated that they frequently use PowerPoint or other slide presentations for lectures or presentations $(86 \%$ in the segment of video-oriented customers). However, differences emerge in the evaluation of PowerPoint presentations. In the text-oriented segment, only $49 \%$ confirm that they regard PPTX presentations as monotonous, whereas this is the case for more than $80 \%$ of the video-oriented users.

\subsection{Potential to Substitute or Enhance Slide Presentations by Explainer Videos}

In a further step, it was determined how often the respondents create slide presentations and whether they can imagine either replacing them with explainer videos or enriching them with explainer videos, for example, by integrating the core results in the form of a video.

On average, respondents create about two slide presentations per month $(M=24.1$ p.a., SD 37.0). The number of slide presentations created varies considerably. On the one hand, $52 \%$ of the respondents mention values of up to ten p.a. (i.e., less than one slide presentation per month), while about $18 \%$ put the total number at more than 40 slide presentations per year. Overall, there is a significant potential to replace slide presentations with explainer videos $(\mathrm{M}=3.9$ p.a. $)$ or to integrate explainer videos $(\mathrm{M}=9.2$ p.a.). With regard to the education and corporate customer segments, there are no significant differences in the average number of slide presentations created per year, but there are differences with regard to the potential for substitution or expansion with explainer videos. The educational segment shows higher values in both aspects (Table 5).

Table 5. Usage of slide presentation and potential for substitution/enhancement by explainer videos

\begin{tabular}{llll}
\hline Media-orientation* & Segment Education & Segment Corporations & Total sample \\
\hline \# slide presentations p.a. & $\varnothing 23.6(100 \%)$ & $\varnothing 24.6(100 \%)$ & $\varnothing 24.1(100 \%)$ \\
...\# potentially substituted & $\varnothing 4.6(20 \%)$ & $\varnothing 3.3(13 \%)$ & $\varnothing 3.9(13 \%)$ \\
...\# potentially enhanced & $\varnothing 11.1(47 \%)$ & $\varnothing 7.5(31 \%)$ & $\varnothing 9.2(38 \%)$ \\
\hline
\end{tabular}

Note. * Question: If you think about the last 12 months, how often did you create presentations with PowerPoint (or other slide presentation programs)? You had indicated that you have created __ (show: ....) PowerPoint presentations in the last 12 months? For how many presentations, could you imagine working with or integrating an explainer video instead of slides created with PowerPoint or other slide presentation programs?

\subsection{Experimental Design: Relevance of Remote Work During the COVID-19 Crisis}

The research results presented in the experiment are results of a representative survey in 4 European countries (Krämer \& Hercher, 2021). Specifically analyzed was the extent to which respondents had worked in home office in Nov. 2020, their current experience with working and how relevant home office is seen to be in the near future. The study results thus relate to a highly topical and very strongly discussed issue during the COVID-19 pandemic. In order to examine the extent to which the study participants are affected by a change in the organization of work, several statements were presented to describe the current work status. Since the question design used was identical to the study on the topic of home office, results can be directly compared (Table 6).

When comparing the structure of the responses, it becomes clear that the simpleshow customer sample deviates significantly from the structures of a representative sample of the German population. While more than $80 \%$ of respondents in the simpleshow sample stated that they work from home more often or completely, only $22 \%$ of 
respondents in the reference study did so $(\mathrm{p}<0.001)$.

Due to the specific characteristics of the simpleshow customers, namely on the one hand employees in the field of education (school, universities) and on the other hand larger companies (often with a strong service orientation), these deviations are explainable and plausible.

Table 6. Statements concerning the current status of work

\begin{tabular}{|c|c|c|}
\hline Evaluation of statements $^{*}$ & Simpleshow sample (2021) & Reference Germany $(2020)^{* *}$ \\
\hline I still go about my work & $41 \%$ & $64 \%$ \\
\hline I go about my work, albeit on short time & $3 \%$ & $13 \%$ \\
\hline I work more often/completely from home & $81 \%$ & $22 \%$ \\
\hline My workplace is closed & $6 \%$ & $5 \%$ \\
\hline I have regular contact with my colleagues/employees & $56 \%$ & $9 \%$ \\
\hline I am off work/on vacation because of the Corona crisis & $0 \%$ & $3 \%$ \\
\hline Because of the Corona crisis I became unemployed & $0 \%$ & $1 \%$ \\
\hline None of the above statements apply & $1 \%$ & $1 \%$ \\
\hline
\end{tabular}

Note. * Question: Which statements are true for you personally in the current time of the Corona crisis? (Multiple answers except last position)

** Krämer and Hercher, 2021.

\subsection{Knowledge Test on Remote Work During the COVID-19 Crisis}

The results for the knowledge test show a considerable scatter. While on the one hand about $19 \%$ of the test subjects achieved the maximum result of 7 points ( $25 \%$ with 6 or 7 points), $9 \%$ of the participants achieved negative results (the number of wrong answers exceeded the number of correct answers).

Figure 2 illustrates further insights into the results of the knowledge test. Here, the mean point scores for the knowledge test are shown in the middle. Additionally, tests for statistical significance of the mean differences and the effect sizes (Cohen's d) as a measure of the relevance of the differences are shown.
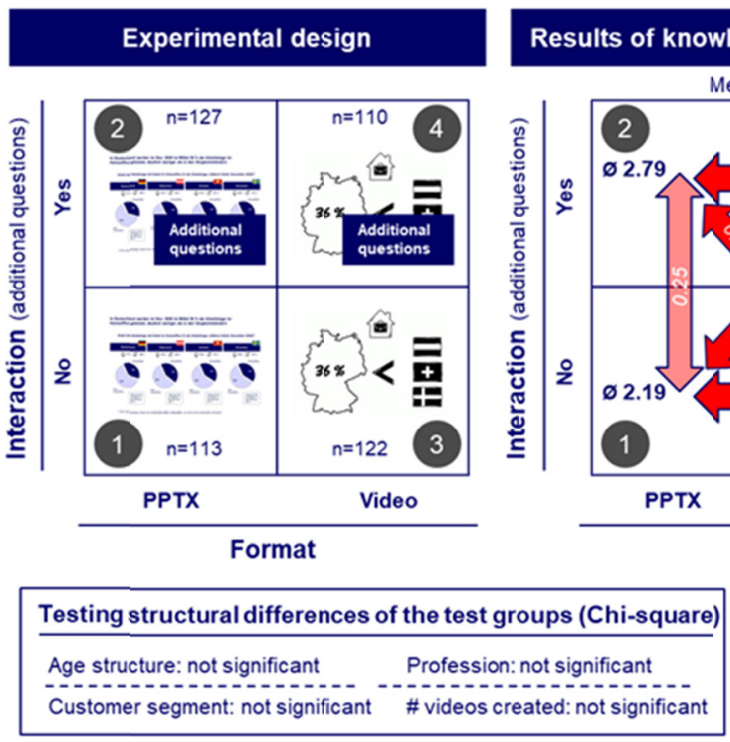

\section{Results of knowledge transfer (pts.)}

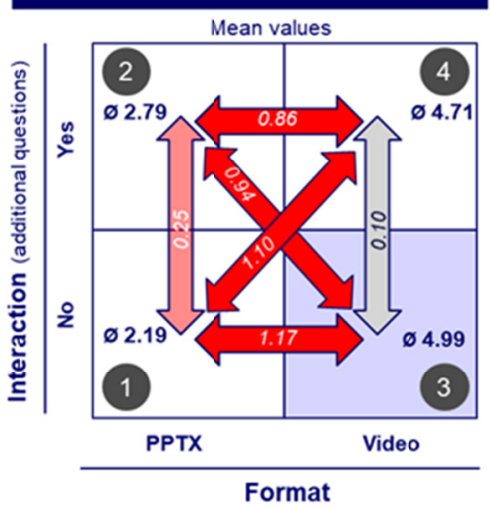

\section{Statistical tests (mean values)}

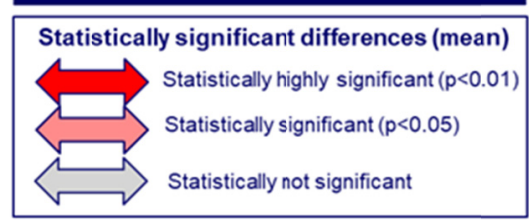

\begin{tabular}{|c|c|}
\hline Effect size & $\begin{array}{l}\text { Effect size Cohen's } d \\
(0.2-<0.5=\text { small) }\end{array}$ \\
\hline & $\begin{array}{l}\text { Effect size Cohen's d } \\
(0.5-<0.8=\text { medium })\end{array}$ \\
\hline & $\begin{array}{l}\text { Effect size Cohen's d } \\
(0.8+=\text { very large })\end{array}$ \\
\hline
\end{tabular}

\begin{tabular}{|c|c|c|}
\hline \multicolumn{3}{|c|}{ Two-factor analysis of variance $F(3,468)=41.7, p<0.01)^{\star}$} \\
\hline Constant term & $p<0.001$ & $n p 2=0.713$ \\
\hline Factor: Format** & $p<0.001$ & $n p 2=0.206 f=0.42$ \\
\hline $\begin{array}{l}\text { Factor: Interaction: } \\
\text { Factor: Format x Interaction: }\end{array}$ & $\begin{array}{l}p=0.446 \\
p=0.043\end{array}$ & $\begin{array}{l}\mathrm{np} 2=0.001 \mathrm{f}=0.01 \\
\mathrm{np2}=0.009 \mathrm{f}=0.09\end{array}$ \\
\hline
\end{tabular}

1) Knowledge test with a total of 5 questions on the presented content; minimum value -5 ; maximum value +7 .

Figure 2. Results from experimental design: knowledge transfer (objective view)

Furthermore, the effects of the factors presentation type and interaction ("additional questions") were examined using a two-factor analysis of variance. Levene's test is used to inspect the null hypothesis that the variances of the groups do not differ. In our case, the Levene test is not significant $(p=0.38)$, so that homogeneous variances can be assumed. The results indicate that the knowledge transfer in the group (\#3) with explainer video (without 
interaction) is best $(\mathrm{M}=4.99)$, the test group (\#4) with explainer video and with interaction comes to a slightly lower level $(\mathrm{M}=4.71$; differences not statistically significant, no relevant effect size). The smallest effect of knowledge transfer occurs in the test group (\#1) with the presentation via PPTX (without interaction). Here, only a mean value of 2.19 points is reached. In contrast, the group with presentation via PPTX and additional interaction achieves a better value $(M=2.79)$. This difference is statistically significant $(p<0.05)$ and shows a small effect size $(\mathrm{d}=0.25)$. At the same time differences between the test groups with presentation via PPTX or explainer video are statistically highly significant and show larger, partly extremely large, effect sizes $(\mathrm{d}>1.0)$. The analysis of variance confirms that the factor presentation format has a significantly stronger effect on the knowledge transfer than the interaction factor. As can be seen in Figure 2, there is a main effect by the presentation format on the knowledge effect $(\mathrm{F}(1,470)=121.19, \mathrm{p}<0.001, \eta \mathrm{p} 2=0.21)$. No main effect is evident for the interaction factor $(\mathrm{F}(1,470)=0.581, \mathrm{p}=0.446, \eta \mathrm{p} 2=0.001)$. Thus, the knowledge effect appears to be independent of the interaction. The interaction term is statistically significant, but the effect size is rather low.

\subsection{Length of Viewing Time and Resulting Input/Output-Ratios}

When interpreting the knowledge transfer, it seems necessary to check whether the different test groups spent the same amount of time to have the study results explained to them. Finally, it is to be expected that a more intensive examination of the topic leads to improved effects in knowledge transfer (Krämer \& Böhrs, 2016). Basically, both with the presentation of slides and the video, the participants had the possibility to determine for themselves how long the presentation should take. The explainer video (EV) was played for a fixed time. In addition, there was also the possibility to spool the video and to repeat or shorten the video. During the slide presentation, the test persons had to actively request the insertion of the next page. In the interview, the total time for viewing the entire presentation was measured. With regard to viewing time, the following results can be noted (Table 7):

- The interaction, i.e., the processing of additional questions on the topic leads to a significant extension of the viewing time (including answering additional questions as part of the interaction). For the PPTX presentation the viewing time is increased from 84 seconds (without interaction) to 161 seconds (with interaction) ( $+92 \%$; for the explainer video the increase is from 115 to 226 seconds $=+97 \%$ ).

- Shortest average viewing time was measured for the PPTX presentation without interaction ("no additional questions"; $84 \mathrm{sec}$.).

- The total duration of the explainer video without interaction was 110 seconds. The mean effective viewing time was on a similar level, i.e., participants with video generally accepted the pacing of the video and watched the video in its entirety.

- Group \#3 does not only achieve the absolute best result in knowledge transfer, but also the relatively best result of the four test groups when the knowledge effect is evaluated in relation to the viewing time.

Table 7. Knowledge improvement related to time spent to watch the video

\begin{tabular}{lllll}
\hline Mean parameters & $\begin{array}{l}\text { \#1 PPTX format/no } \\
\text { interaction }\end{array}$ & $\begin{array}{l}\text { \#2 PPTX format / } \\
\text { interaction }\end{array}$ & $\begin{array}{l}\text { \#3 EV format / no } \\
\text { interaction }\end{array}$ & $\begin{array}{l}\text { \#4 EV format / } \\
\text { interaction }\end{array}$ \\
\hline Knowledge post-level (mean points) & $\varnothing 2.19$ & $\varnothing 2.79$ & $\varnothing 4.99$ & $\varnothing 4.72$ \\
Viewing time (sec.) & $\varnothing 84$ & $\varnothing 161$ & $\varnothing 115$ & $\varnothing 226$ \\
Efficiency index & 100 & 65 & 165 & 78 \\
\hline
\end{tabular}

Note. ${ }^{*}$ Index $=100$ for PPTX presentation without interaction (improved knowledge level in relation to time spend to watch the video (sec.)). Interaction $=$ additional questions.

\subsection{Customer Evaluation: Subjective Perspective of the Participants}

In addition to the objective recording of the effects on knowledge transfer (knowledge test), the respondents were also asked to directly give a subjective assessment on the presentation they regarded. Ten different statements were used for this purpose (rating scale from $1=\mathrm{I}$ fully agree to $5=\mathrm{I}$ fully disagree). Also here, considerable differences in level between PPTX and the EV are apparent, with a significantly more positive rating in each case for the EV (Table 8). In the Table, in addition to the mean values of the rating scale scores, the normalized percentage deviations compared to test group 3 are given in parentheses. Main results are:

- $30-35 \%$ of test group members with PPTX (\#1/2) agreed with the statement "I understood the content 
well" (35-49\% disagreed, $\mathrm{M}=3.0-3.3$ ), at the same time groups with explainer video reached $88-89 \%$ ( $3-4 \%$ disagreed, $M=1.7-1.8$ ).

- From the subjects' point of view, the presentation of the results via explainer video is judged to be overwhelmingly entertaining $(\mathrm{M}=2.0-2.1)$, while this is not true in case of slide presentations (judgement in test group \#1 differs more than 50\% from test group \#3, indicating a large effect size).

- The statement "Took me a long time to grasp the content" is agreed with more strongly in the groups with PPTX presentation (61-69\% M $=2.1-2.3)$, and only to a lesser extent in subjects with explainer video $(7-15 \%, M=4.0)$.

Table 8. Statements concerning the presentation of study results on relevance of home office (mean values)

\begin{tabular}{lllll}
\hline $\begin{array}{l}\text { Evaluation of statements based on } \\
\text { a 5-point rating scale }\end{array}$ & $\begin{array}{l}\text { \#1 PPTX format / } \\
\text { no interaction }\end{array}$ & $\begin{array}{l}\text { \#2 PPTX format / } \\
\text { interaction }\end{array}$ & $\begin{array}{l}\text { \#3 EV format / } \\
\text { no interaction }\end{array}$ & $\begin{array}{l}\text { \#4 EV format / } \\
\text { interaction }\end{array}$ \\
\hline I understood the content well & $3.27(37 \%)^{* *}$ & $3.02(31 \%)$ & 1.80 & $1.71(-2 \%)$ \\
The presentation was well done & $3.27(36 \%)$ & $3.03(30 \%)$ & 1.84 & $1.76(-2 \%)$ \\
The content was well structured & $3.30(37 \%)$ & $3.03(30 \%)$ & 1.84 & $1.91(2 \%)$ \\
I liked the style and the way it was done & $3.79(48 \%)$ & $3.43(39 \%)$ & 1.89 & $2.01(3 \%)$ \\
The presentation was entertaining & $4.24(53 \%)$ & $3.71(40 \%)$ & 2.12 & $1.98(-4 \%)$ \\
I can remember the content well & $3.85(38 \%)$ & $3.50(29 \%)$ & 2.34 & $2.16(-4 \%)$ \\
The presentation appeals to me emotionally & $4.19(41 \%)$ & $3.86(33 \%)$ & 2.56 & $2.52(-1 \%)$ \\
The presentation increased my interest in the topic & $3.88(24 \%)$ & $3.64(18 \%)$ & 2.91 & $2.80(-3 \%)$ \\
It motivated me to engage more with the topic & $3.87(19 \%)$ & $3.77(17 \%)$ & 3.11 & $2.97(-3 \%)$ \\
Took me a long time to grasp the content & $2.06(-49 \%)$ & $2.28(-44 \%)$ & 4.02 & $3.95(-2 \%)$ \\
\hline
\end{tabular}

Note. * Question: What do you think of the presentation of the study results that you just saw? Pleasee use a scale from $1=\mathrm{I}$ fully agree to $5=$ I fully disagree.

** In parentheses normalized percentage deviatons: absolute difference (group - group 3) in relationn to scale width (4); (Note 3). Interaction $=$ additional questions.

The main findings show structurally similar results to the previously measured knowledge effect (objective view). Participants in the explainer video test groups (\#3/4) confirmed a comparatively better absorption of the information ("I understood the content well"), a better ability to reproduce the core results presented ("I can remember the content well") and a stronger activation ("It motivated me to engage more with the topic"). Figure 3 illustrates the statistically significant and relevant results in terms of effect size. A meaningful effect due to interaction - albeit small (d>0.2) - can be identified in the test groups with PPTX (\#1-2).

\section{"I understood the content well"1)}
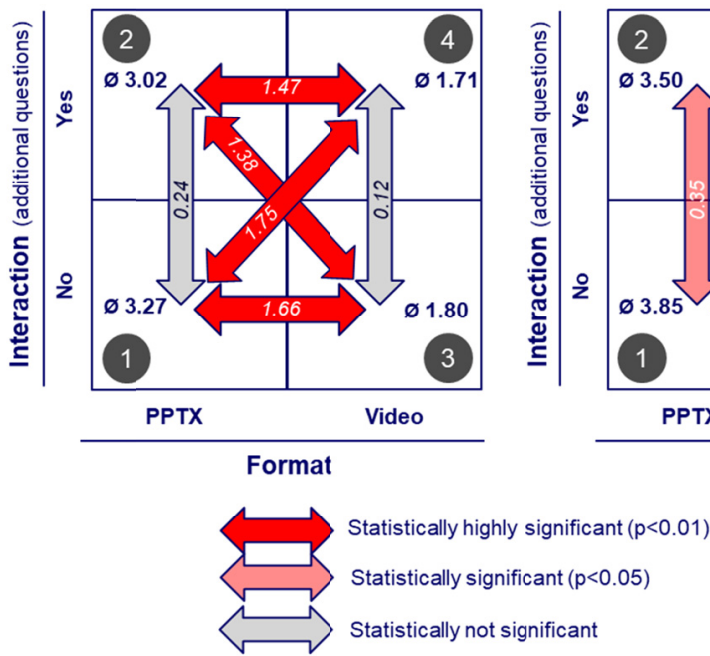
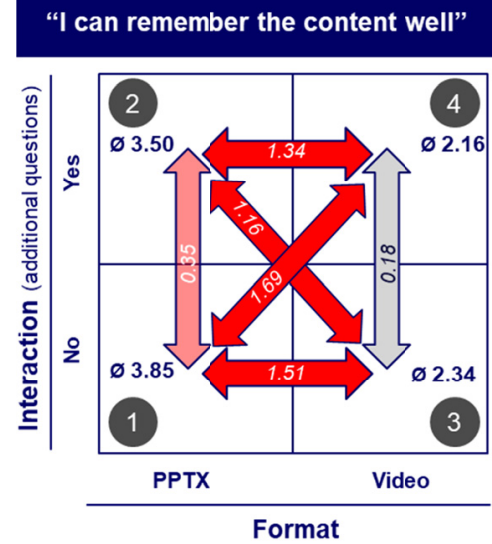

"It motivated me to engage more with the topic"

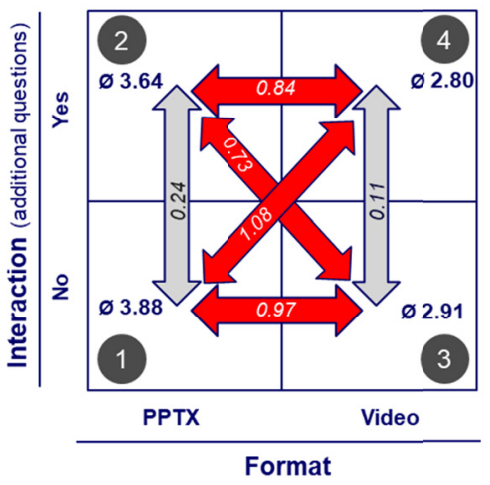

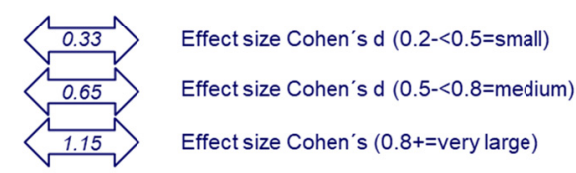

1) What do you think of the presentation of the study results that you just saw? Scale from $1=$ fully agree to $5=$ fully disagree.

Figure 3. Results from experimental design: evaluation of statements/subjective view 


\section{Discussion}

In the following, some interrelations will be examined in more detail. This concerns different aspects: (a) the dependencies between presentation form, viewing time (pacing) and learning success, (b) the link between objective learning success and the subjective evaluation and (c) the aspect of the verbalization or the missing speaker in the PowerPoint presentation.

The experimental design leads to relatively clear results with regard to the target variable of knowledge transfer for the test groups with explainer video. To the authors' knowledge, this is the first study to investigate and quantify the learning effects of slide presentations and explainer videos in a direct comparison (in a non-educational environment). The results remain unambiguous when considering the better results on knowledge transfer in relation to time spent. Krämer and Böhrs (2016) introduced this approach in order to measure efficiency of knowledge transfer. However, the question arises how the comparatively short viewing time in the test group PPTX presentation without interaction can be explained. One explanation is that in the case of the explainer video, the test subjects accept the timing of the video shown (they likely perceive it as a system pacing, although they had the opportunity for an individualized pacing), whereas in the case of the slide presentation, the timing/pacing is perceived flexible (learner pacing). Obviously, during the experiment some subjects cut short the viewing time in this case. The state of academic research to date would lead one to expect that learning speed meant mainly an extension of the viewing time, i.e., subjects make use of the possibility to select relevant information and to organize and integrate it into a mental model (Mayer \& Chandler, 2001). In contrast, the viewing time in our study is shortened when results from research are presented via slides. However, similar effects have already been pointed out by Stiller et al. (2009). When defining the experimental design, the project team explicitly excluded the possibility of providing each participant with a fixed time budget, since learning with instructional animations was expected to overstretch limited working memory (see Hatsidimitris \& Kalyuga, 2013). Since the time required to process the information shown during the test can vary from person to person, self-determined timing was allowed. Obviously, presentation format and pacing are interlinked (see Koć-Januchta et al., 2020). However, if test persons are classified in groups with comparable viewing time, the superiority of the explainer video over the slide presentation persists (see Appendix C).

The results of the experiment with regard to the effect of presentation format and interaction are similar, regardless of whether the objective results of the knowledge test are considered or the self-assessment of the test subjects. This is remarkable insofar that other studies have come to the conclusion subjects would overestimate the effective learning success, especially in the context of explainer video. Kulgemeyer and Wittwer (2021) investigated this relationship with students majoring in physics and concluded: "While the experimental group watched a video introducing the concept of force relying on misconceptions, the control group watched the scientifically correct video. Both videos were comparable in terms of comprehensibility and duration. In the posttest, the experimental group believed that the video was scientifically correct, well-explained, and that they do not require further instruction to understand the concept." They refer to other empirical findings suggesting that humans have difficulties distinguishing between their feelings of efficacy and their actual level of understanding, an effect Wiley (2019) called "seduction effect" of pictures.

Behind the factor "presentation form explainer video" there were partial factors, which were different compared to the presentation form slide presentation. In addition to the timing and the animation, the absence of a speaker should also be mentioned (the slide presentation lacks acoustic support). Particularly the interaction of spoken text and moving images is seen as a determinant for an improved learning effect. As Stiller et al. (2009) state: "the modality principle of multimedia design recommends using spoken rather than written texts in conjunction with dynamic or static pictures, because learners learn more effectively in computer based and book-based environments when spoken texts are used." The cognitive theory of multimedia learning (CTML; Mayer, 2001) helps to explain this mechanism, assuming that pictorial and verbal information is processed in two separate systems. Both are functionally independent of each other, although they can interact. Written words are initially processed in the visual/pictorial channel before they move to the auditory/verbal channel in the working memory. When spoken words are presented simultaneously with text during a presentation, there is a third and detrimental effect at work, called the redundancy principle (Sweller, 2005).

In order to classify the results, it should be noted that the comparatively poor results of the slide presentation with regard to knowledge transfer-as well as the subjective assessment by the recipients - can possibly be improved if a time frame is given for the viewing (e.g., if the slides are presented as a video) or if the results are explained verbally (i.e., by integrating a speaker in an animated slide presentation or by personally presenting results in a live presentation). 


\section{Implications}

The most important findings for the future use of explainer videos are: (a) use of explainer videos to convey core messages, (b) use of options to substitute or enhance PowerPoint presentations by explainer videos and (c) examine need for interactive elements.

\subsection{Use of Explainer Videos to Convey Core Messages}

When Laaser and Toloza (2017) claim "the cartoon type of explainer videos is limited to easily understandable short topics and is more entertainment than a serious academic presentation", then this does not necessarily apply to all explainer videos. In fact, it should be noted that depending on the supplier of explainer videos, a more or less professional creation of didactically efficient explainer videos is made possible. The range of offerings is very fragmented (Böhrs \& Krämer, 2020). The format of the explainer video is less responsible for the learning success, but rather the quality of the explanation. For example, Kulgemeyer (2018) compared high explaining quality (HE) video and one low explaining quality (LE), concluding that "the HE group outperformed the LE group in the achievement of declarative knowledge."

Therefore, general statements are problematic or inaccurate in specific cases. As was shown, the explainer video in the experiment demonstrates a high level of effectiveness and efficiency in the transfer of knowledge. However, the application spectrum is limited to short presentations, as Sedej (2019) highlights: "With explainer videos companies can explain a business idea, product, or project in a one-to-three-minute-long video with informational, educational, and even entertaining value at the same time."

Against this background, it is recommended that explainer videos should be used, for example, where study results are summarized in a highly condensed form (Kulgemeyer, 2018). These experimental results correspond with the findings of other investigations, if for example Rusli et al. (2014) conclude that "learning with multimedia using animation visualization presentation is better than the static visualization presentation".

\subsection{Use Options to Substitute or Enhance PowerPoint Presentations by Explainer Videos}

Whether PowerPoint can maintain its dominant position as a medium in the classroom and in companies depends on how the presentation format can be adapted to the changing needs of the target audience. The meta-analysis by Baker et al. (2018), which focused on the use of PowerPoint in education, was conducted to summarize the effectiveness of PowerPoint compared to traditional instruction on cognitive skills, concludes "that PowerPoint had no effect on learning." In Brewster's (2011) opinion, PowerPoint shows poor performance, especially in summarizing important content, therefore dashboards are recommended instead of slides. Other authors propose using Augmented Reality (AR)-assisted tools instead of PowerPoint presentations (experimental research by Zhang et al. (2020) showed that the AR-assisted lecture was significantly more effective than the PPTX-based lecture). Based on their research results, explainer videos can also replace PowerPoint presentations in this framework. However, it is also conceivable to dovetail explainer videos more closely with slide presentations, for example in the case of longer presentations.

Videos could be used especially in areas where either the knowledge base is at a very low level, or the involvement of consumers is rather low. Based on these results, it is expected that the knowledge improvements in other areas could be even more substantial than in the test (the majority of respondents were very interested in the topic). Furthermore, in case the interest is low potential users of explainer video only have a limited willingness to spend a longer time to watch the video (Krämer \& Böhrs, 2016). This emphasizes the crucial role of a short video time.

\subsection{Examine Need for Interactive Elements}

Integrating interactive elements can not only lead to an improved knowledge transfer, but also to better perception by the target audience, to an increased interest in the presented topic as well as to promote engagement (Evans \& Gibbons, 2007; Zhang et al., 2006). However, based on our findings, this is rather the case for the PowerPoint presentation. This corresponds with the results of Jordan ad Papp (2014), pointing out that PowerPoint can easily be used in an interactive manner. They recommend to "pose discussion questions or introduce short quizzes or group application exercises into presentations to allow time for interaction, discussion and reflection."

In our experimental design, slightly positive effects were obtained by superimposing additional questions on the topic (factor interaction). It is to be expected that the effects are significantly more positive for longer presentations (e.g., $45 \mathrm{~min}$ ). No positive effects resulted from the interaction in the presentation form explainer video. This can possibly be due to the fact that the presentation of results in the video was already highly compressed and well-structured; the presentation of the study results was very short and the presentation was 
optimized by storylining. Hence, no incremental positive effects can be achieved by forcing the test subjects to deal more intensively with the topic. In longer presentations, interaction may have a positive effect (Geri, 2017). However, in our analysis we only focused on a very short and very condensed result presentation. Therefore, it is recommended to make the use of interactive elements dependent on the presentation form and especially length, taking into account that the efficiency of knowledge transfer was lowest in the explainer video test group with interaction (\#4).

\section{Conclusion}

Numerous researchers have recently proposed principles for the design of effective presentations for improving the knowledge transfer of slide presentations, both in the education as well as in the business environment. Our study contributes to a better understanding of the effectiveness and efficiency of knowledge transfer depending on the type of presentation. Overall, the study shows that a classic presentation of research results based on PowerPoint slides (without a speaker, the viewing time is determined by the target persons themselves) is inferior to a presentation via explainer video. This correlates not only with a potential for substituting short slide presentations with explainer videos, but also with the integration of explainer videos into slide presentations.

Some special limitations of this experiment must be acknowledged. (1) The content covered is relatively limited, scientific, and factual, (2) time to present results from research was short, and (3) performance measures were not of the problem-solving type and only concerned declarative knowledge. In addition, it should be noted that the study does not claim to be able to provide results representative of the population, but representative results for simpleshow's customers. However, a comparison of the media preferences of our own sample with representative studies shows structural similarities. Nevertheless, there is a need for research to repeat the study based on a representative sample of the population and to investigate the effects of verbal support in PowerPoint presentations.

\section{Acknowledgments}

The authors are grateful to Rogator AG, Nuremberg, for the provision of survey software, the programming of the questionnaire and the entire data management as well as Dr. Gerd Wilger, Dr. Robert Bongaerts (exeo Strategic Consulting) and Lisa Burschik (simpleshow) for substantive comments and input to the study and David Weber from simpleshow for creating the video material.

\section{References}

Baker, J. P., Goodboy, A. K., Bowman, N. D., \& Wright, A. A. (2018). Does teaching with PowerPoint increase students' learning? A meta-analysis. Computers \& Education, 126, 376-387. https://doi.org/10.1016/j.compedu.2018.08.003

Böhrs, S., \& Krämer, A. (2020). Explainer-Videos: Zwischen Agenturleistung und DIY-Tool. Marketing Review St. Gallen, 37(2), 70-78.

Brewster, K. (2011). Dashboards-the new PowerPoint? Shifting the Boundaries of Research, 246-258.

Chou, P. N., Chang, C. C., \& Lu, P. F. (2015). Prezi versus PowerPoint: The effects of varied digital presentation tools on students' learning performance. Computers \& Education, 91, 73-82. https://doi.org/10.1016/j.compedu.2015.10.020

Ciriello, R. F., Richter, A., \& Schwabe, G. (2015). PowerPoint use and misuse in digital innovation. Twenty-Third European Conference on Information Systems (ECIS), Münster.

Clark, J. (2008). PowerPoint and pedagogy: Maintaining student interest in university lectures. College Teaching, 56(1), 39-44. https://doi.org/10.3200/CTCH.56.1.39-46

Derouin, R. E., Fritzsche, B. A., \& Salas, E. (2005). E-learning in organizations. Journal of Management, 31(6), 920-940. https://doi.org/10.1177/0149206305279815

Gabriel, Y. (2008). Against the tyranny of PowerPoint: Technology-in-use and technology abuse. Organization Studies, 29(2), 255-276. https://doi.org/10.1177/0170840607079536

Gabrielle, B. R. (2010). Speaking PowerPoint: The new language of business. Insights Publishing.

Gamble, S. (2016). Visual Content Marketing: Leveraging Infographics, Video, and Interactive Media to Attract and Engage Customers. John Wiley \& Sons.

Garrison, D. R., \& Shale, D. (1990). A new framework and perspective. In D. R. Garrison \& D. Shale (Eds.), Education at a distance: From issues to practice (pp. 123-133). Malabar, Florida: Robert E. Krieger Publishing Company. 
Geri, N., Winer, A., \& Zaks, B. (2017). Challenging the six-minute myth of online video lectures: Can interactivity expand the attention span of learners? Online Journal of Applied Knowledge Management (OJAKM), 5(1), 101-111. https://doi.org/10.36965/OJAKM.2017.5(1)101-111

Graham, B. (2015). Power up your PowToon Studio project. Packt Publishing Ltd.

Khalil, H., \& Ebner, M. (2013). Interaction possibilities in MOOCs-how do they actually happen (pp. 1-24)? In 3rd International Conference on Higher Education Development" Future Visions for Higher Education Development".

Hampapur, A., \& Jain, R. (1998). Chapter 9: Video data management systems: Metadata and architecture. In Multimedia Data Management, 1998, McGraw-Hill.

Hatsidimitris, G., \& Kalyuga, S. (2013). Guided self-management of transient information in animations through pacing and sequencing strategies. Educational Technology Research and Development, 61(1), 91-105. https://doi.org/10.1007/s11423-012-9276-z

Hertz, B., van Woerkum, C., \& Kerkhof, P. (2013). Wetenschappelijke presentaties met PowerPoint. Schadelijke software? (Scientific presentations with PowerPoint. Detrimental software?). In R. Boogaart \& H. Janssen (Eds.), Studies in taalbeheersing (pp. 125-134). Assen, Netherlands: Van Gorcum

Jordan, L. A., \& Papp, R. (2014). PowerPoint ${ }^{\circledR}$ : It's not "yes" or "no": It's "when" and "how". Research in Higher Education Journal, 22, 1-11.

Koć-Januchta, M. M., Höffler, T. N., Prechtl, H., \& Leutner, D. (2020). Is too much help an obstacle? Effects of interactivity and cognitive style on learning with dynamic versus non-dynamic visualizations with narrative explanations. Educational Technology Research and Development, 68(6), 2971-2990. https://doi.org/10.1007/s11423-020-09822-0

Krämer, A., \& Böhrs, S. (2015). Experiences and Future Expectations Towards Online Courses-an Empirical Study of the B2C and B2B Segments. Journal of Education and Training Studies, 1(4), 23-31. https://doi.org/10.11114/jets.v4i1.1104

Krämer, A., \& Böhrs, S. (2016). International study on the use and effects of different explainer video formats. Berlin.

Krämer, A., \& Böhrs, S. (2017a). Erklärvideos als effektives und effizientes Marketing-Instrument. Marketing Review St. Gallen, 34(2), 54-61.

Krämer, A., \& Böhrs, S. (2017b). How Do Consumers Evaluate Explainer Videos: An Empirical Study on the Effectiveness and Efficiency of different Explainer Video Formats. Journal of Education and Learning, 6(1), 254-266. https://doi.org/10.5539/jel.v6n1p254

Krämer, A. (2016). Experimental-Designs als (neue) Basis der Marketingforschung. Präsentation auf dem Rogator-Kundentag, Nürnberg, 23. Juni 2016.

Krämer, A., \& Hercher, J. (2021). New Work in Zeiten von Corona: Wenig Änderung im Berufsprestige, viel Änderung bei Homeoffice-Tätigkeiten. Rogator / exeo untersuchen zum zweiten Mal das Berufsprestige und die Homeoffice-Tätigkeit in Deutschland, Österreich, der Schweiz und Schweden, 3. Februar 2021. Retrieved from https://www.rogator.de/new-work-corona-berufsprestige-homeoffice/

Kulgemeyer, C. (2018). A framework of effective science explanation videos informed by criteria for instructional explanations. Research in Science Education, 1-22. https://doi.org/10.1007/s11165-018-9787-7

Kulgemeyer, C., \& Wittwer, J. (2021). When Learners Prefer the Wrong Explanation: Misconceptions in Physics Explainer Videos and the Illusion of Understanding. https://doi.org/10.31234/osf.io/q36zf

Laaser, W., \& Toloza, E. A. (2017). The changing role of the educational video in higher distance education. The International Review of Research in Open and Distributed Learning, 18(2). https://doi.org/10.19173/irrodl.v18i2.3067

Lane, P. (2019). Spark Video Strikes Back: Reigniting Learning and Practice in Presentations in a PowerPoint Universe. CELE Journal, 27, 76-105.

Lind, G. (2014). Effektstärken: Statistische, praktische und theoretische Bedeutsamkeit empirischer Befunde. Retrieved from https://www. uni-konstanz. de/ag-moral/pdf/Lind-2014_Effektstaerke-Vortrag. pdf

Litt, M. (2014). How online video is changing the way B2B marketers engage and convert prospects. Journal of 
Brand Strategy, 3(2), 129-134.

Mayer, R. E., \& Chandler, P. (2001). When learning is just a click away: Does simple user interaction foster deeper understanding of multimedia messages? Journal of Educational Psychology, 93, 390-397. https://doi.org/10.1037/0022-0663.93.2.390

Mayer, R. E. (2001). Multimedia learning. New York, NY: Cambridge University Press. https://doi.org/10.1017/CBO9781139164603

Nandi, D., Hamilton, M., \& Harland, J. (2015). What factors impact student-Content interaction in fully online courses. IJ Modern Education and Computer Science, 7, 28-35. https://doi.org/10.5815/ijmecs.2015.07.04

Paas, F., Renkl, A., \& Sweller, J. (2004). Cognitive load theory: Instructional implications of the interaction between information structures and cognitive architecture. Instructional Science, 32(1), 1-8. https://doi.org/10.1023/B:TRUC.0000021806.17516.d0

Pamadhi, H., \& Zulfiati, H. M. (2019). Improving The Ability of Writing Art Criticism Through Blended Learning (p. 255). In ICOSS 2018: Proceedings of International Conference of Social Science, ICOSS 2018, Denpasar, Indonesia. European Alliance for Innovation. https://doi.org/10.4108/eai.21-9-2018.2281188

Penciner, R. (2013). Does PowerPoint enhance learning? Canadian Journal of Emergency Medicine, 15(2), 109-112. https://doi.org/10.2310/8000.2013.130756

Riding, R., \& Douglas, G. (1993). The effect of cognitive style and mode of presentation on learning performance. British Journal of Educational Psychology, 63(2), 297-307. https://doi.org/10.1111/j.2044-8279.1993.tb01059.x

Rusli, M., Ardhana, I. W., Sudana, I. N. D., \& Kamdi, W. (2014). The Effect of Presentation Strategy on Multimedia Learning-Animation vs Static Visualization-and Learning Style to Learning Result. Academic Research International, 5(1), 216-226.

Sarstedt, M., \& Mooi, E. (2014). A concise guide to market research. The Process, Data, and MethodsUsing IBM SPSS Statistics, Springer-Verlag Berlin Heidelberg. https://doi.org/10.1007/978-3-642-53965-7

Schär, S., \& Krueger, H. (2000). Using new learning technologies with multimedia. IEEE Multimedia, 7(3), 40-51. https://doi.org/10.1109/93.879767

Schmelzle, J. (2014). 5 Rules for explaining things simply. Retrieved from a simpleshow whitepaper.

Sedej, T. (2019). The digital economy: The use of explainer videos in SMEs' communication. International Journal of Diplomacy and Economy, 5(2), 150-162. https://doi.org/10.1504/IJDIPE.2019.106765

Stiller, K. D., Freitag, A., Zinnbauer, P., \& Freitag, C. (2009). How pacing of multimedia instructions can influence modality effects: A case of superiority of visual texts. Australasian Journal of Educational Technology, 25(2), 184-203. https://doi.org/10.14742/ajet.1149

Sullivan, G. M., \& Feinn, R. (2012). Using effect size — or why the P value is not enough. Journal of Graduate Medical Education, 4(3), 279-282. https://doi.org/10.4300/JGME-D-12-00156.1

Susskind, J. E. (2008). Limits of PowerPoint's power: Enhancing students' self-efficacy and attitudes but not their behavior. Computers \& Education, 50(4), 1228-1239. https://doi.org/10.1016/j.compedu.2006.12.001

Sweller, J. (2005). The redundancy principle in multimedia learning. In R. E. Mayer (Ed.), The Cambridge handbook of multimedia learning (pp. 159-167). New York, NY: Cambridge University Press. https://doi.org/10.1017/CBO9780511816819.011

Tabbers, H. K., \& de Koeijer, B. (2010). Learner control in animated multimedia instructions. Instructional Science, 38, 441-453. https://doi.org/10.1007/s11251-009-9119-4

Tu, D. L. (2015). Feature and Narrative Storytelling for Multimedia Journalists. CRC Press. https://doi.org/10.4324/9781315851297

Tufte, E. R. (2003). The cognitive style of PowerPoint.

van Merriënboer, J. G., \& Sweller, J. (2005). Cognitive load theory and complex learning: Recent developments and future directions. Educational Psychology Review, 17, 147-177. https://doi.org/10.1007/s10648-005-3951-0

Valdez, A. (2013). Multimedia learning from PowerPoint: Use of adjunct questions. Psychology Journal, 10(1), $35-44$. 
Widmer, K. (2018). Video-Content-Hauptdarsteller in der Unschärfe-Zone. Marketing Review St. Gallen, 35(2), $110-117$.

Wiley, J. (2019). Picture this! Effects of photographs, diagrams, animations, and sketching on learning and beliefs about learning from a geoscience text. Applied Cognitive Psychology, 33(1), 9-19. https://doi.org/10.1002/acp.3495

Wodecki, A. (2018). Artificial intelligence in value creation: Improving competitive advantage. Springer. https://doi.org/10.1007/978-3-319-91596-8

Wright, K. (2004). Screenwriting is storytelling: Creating an A-list screenplay that sells! Penguin.

Zhang, D., \& Nunamaker, J. F. (2003). Powering e-learning in the new millennium: An overview of e-learning and enabling technology. Information Systems Frontiers, 5(2), 207-218. https://doi.org/10.1023/A:1022609809036

Zhang, D., Zhou, L., Briggs, R. O., \& Nunamaker, J. F. (2006). Instructional video in e-learning: Assessing the impact of interactive video on learning effectiveness. Information \& Management, 43(1), 15-27. https://doi.org/10.1016/j.im.2005.01.004

Zhang, J., Yen, S. H., Liu, T. C., Sung, Y. T., \& Chang, K. E. (2020). Studies on Learning Effects of AR-Assisted and PPT-Based Lectures. The Asia-Pacific Education Researcher, 1-10. https://doi.org/10.1007/s40299-020-00533-X

\section{Notes}

Note 1. A total of 825 people started the survey. Only participants whose total interview length was at least 3 minutes and who answered all relevant questions related to the experiment were eligible for data analysis. The sample of 472 participants who qualified is representative of simpleshow's customers.

Note 2. Mayer and Chandler (2001) examined what they termed simple interaction - whether or not participants were able to control the pace of a multimedia presentation by choosing when to start each segment of the presentation. Basically, this option was given in all test groups. Participants in the test group "explainer video" could control start and finish of the viewing time as participants in the test group "slide presentation (PPTX)" could.

Note 3. According to Lind (2014): differences in mean values $>10 \%$ of scale width = "very significant" / "very significant effect".

\section{Appendix A}

\section{Description of Core Segments Education and Corporations}

\begin{tabular}{llll}
\hline Attributes & Level & Segment Education & Segment Corporations \\
\hline Age & $<30$ years & $16.4 \%$ & $4.8 \%$ \\
$\chi^{2}(2)=22.8, \mathrm{p}<0.001, \mathrm{~V}=0.23$ & $30-59$ years & $72.7 \%$ & $89.2 \%$ \\
& $60+$ years & $10.9 \%$ & $6.0 \%$ \\
Gender & Female & $57.7 \%$ & $53.4 \%$ \\
$\chi^{2}(2)=3.16, \mathrm{p}=0.206, \mathrm{~V}=0.08$ & Male & $41.8 \%$ & $46.2 \%$ \\
& Divers & $0.5 \%$ & $0.4 \%$ \\
Employment status & School / study / training & $29.5 \%$ & $0.0 \%$ \\
$\chi^{2}(2)=100.5, \mathrm{p}<0.001, \mathrm{~V}=0.46$ & Employed & $66.4 \%$ & $100.0 \%$ \\
& Not employed & $4.1 \%$ & $0.0 \%$ \\
Video-Cluster* & Video creation and commision & $12.3 \%$ & $9.9 \%$ \\
$\chi^{2}(3)=51.3, \mathrm{p}<0.001, \mathrm{~V}=0.33$ & Video creation, no commision & $70.5 \%$ & $42.9 \%$ \\
& No video creation, but commision & $2.3 \%$ & $13.9 \%$ \\
& No video creation, no commision & $15.0 \%$ & $33.3 \%$ \\
Use of simpleshow video maker & Non-user SVM & $22.7 \%$ & $50.4 \%$ \\
$(\mathrm{SVM}) * *$ & Low-user SVM & $64.1 \%$ & $39.3 \%$ \\
$\chi^{2}(2)=39.0, \mathrm{p}<0.001, \mathrm{~V}=0.29$ & Heavy-user SVM & $13.2 \%$ & $10.3 \%$ \\
\hline Note. $*$ Question: Have you already created explainer videos yourself? And have you already commissioned explainer videos? \\
$* *$ Question: We will now come back to platforms that you can use for explainer videos. You had said that you know the following platforms \\
for explainer videos. First, please tell us: How often do you use them? Heavy User SVM= Frequent or very frequent use.
\end{tabular}




\section{Appendix B}

Preference for Using Videos in the Sample and Reference Study

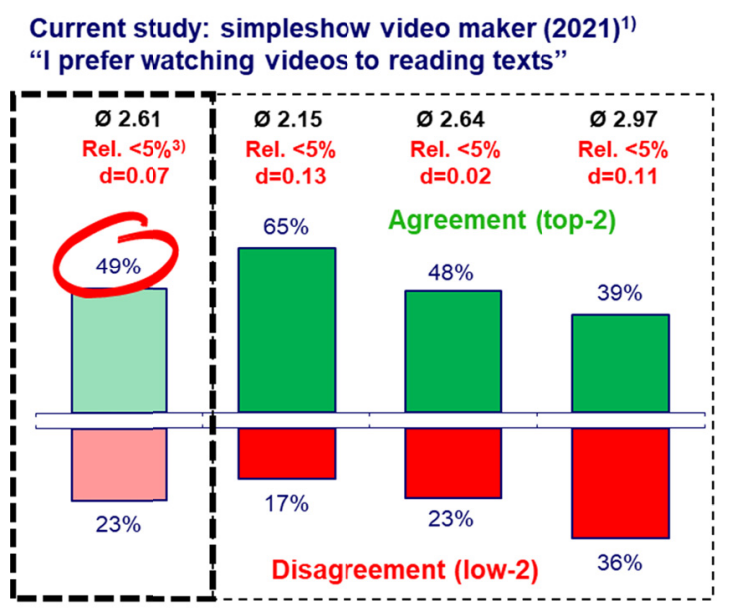

Total $\quad<30$ years $\quad 30-59$ years $60+$ years

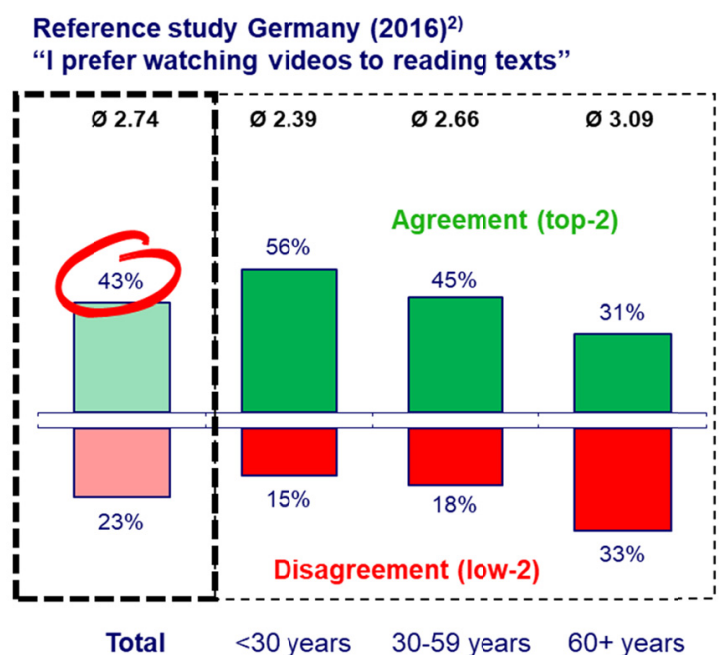

1) To what degree do you agree with the following statements? (Scale from $1=\mid$ fully agree to $5=1$ fully disagree).

2) Krämer \& Böhrs (2016); representative study population for Germany 18+ years, recruitment via online access panel.

3) Verification of effect size: 1 . normalized percentage deviations (Lind, 2014): absolute difference in mean (current study - reference study) in relation to scale width (4); 2 . Cohen's $d$ is used to describe the standardized mean difference of an effect ( $d>0.20$ small effect).

\section{Appendix C}

Knowledge Effect (Mean Points) according to Test Group and Viewing Time

\section{Knowledge test (groups without interaction)}

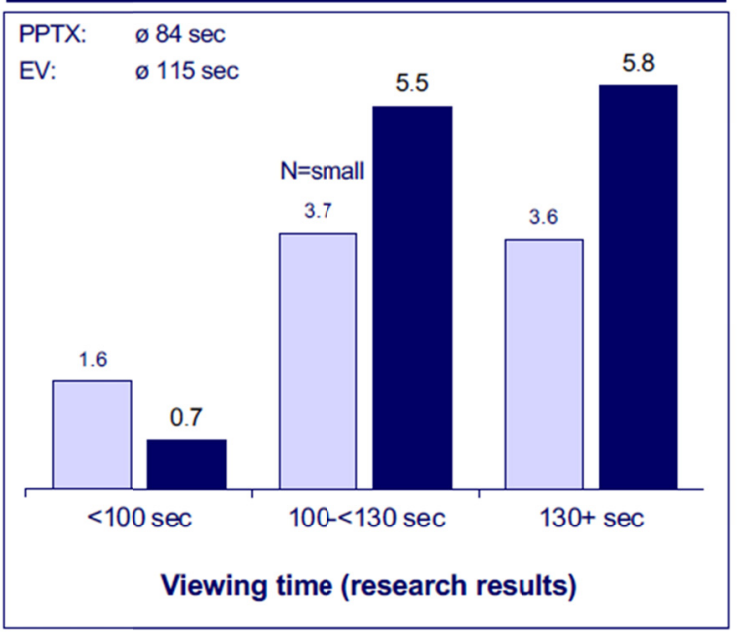

PPTX

Explainer video

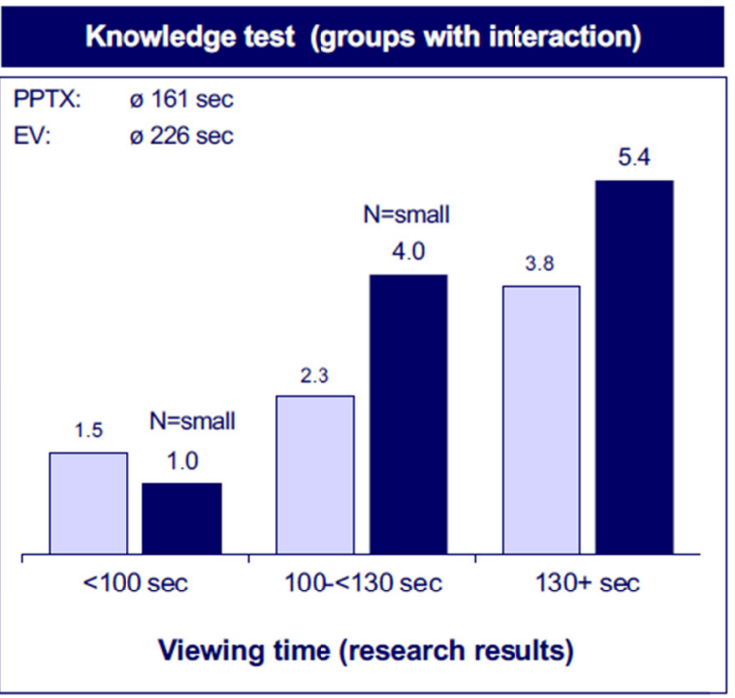

\section{Copyrights}

Copyright for this article is retained by the author, with first publication rights granted to the journal.

This is an open-access article distributed under the terms and conditions of the Creative Commons Attribution license (http://creativecommons.org/licenses/by/4.0/). 